\title{
Critical analysis on the present methods for brain volume measurements in multiple sclerosis
}

\author{
Análise crítica dos métodos atuais para medidas de volume cerebral em esclerose múltipla \\ Yara Dadalti Fragoso', Paulo Roberto Willie², Marcus Vinicius Magno Goncalves ${ }^{3}$, Joseph Bruno Bidin Brooks ${ }^{1}$
}

\begin{abstract}
Objective: The treatment of multiple sclerosis (MS) has quickly evolved from a time when controlling clinical relapses would suffice, to the present day, when complete disease control is expected. Measurement of brain volume is still at an early stage to be indicative of therapeutic decisions in MS. Methods: This paper provides a critical review of potential biases and artifacts in brain measurement in the follow-up of patients with MS. Results: Clinical conditions (such as hydration or ovulation), time of the day, type of magnetic resonance machine (manufacturer and potency), brain volume artifacts and different platforms for volumetric assessment of the brain can induce variations that exceed the acceptable physiological rate of annual loss of brain volume. Conclusion: Although potentially extremely valuable, brain volume measurement still has to be regarded with caution in MS.
\end{abstract}

Keywords: multiple sclerosis; brain; atrophy; gray matter.

RESUMO

Objetivo: 0 tratamento da esclerose múltipla (EM) evoluiu rapidamente de um tempo onde o controle clínico dos surtos era suficiente para o momento atual, quando se almeja o completo controle da doença. Medidas de volume cerebral ainda estão em fases iniciais para utilização nas decisões terapêuticas na EM. Métodos: Este artigo fornece uma revisão crítica de potenciais vieses e artefatos na volumetria cerebral utilizada no seguimento de pacientes com EM. Resultados: Condições clínicas (como hidratação ou ovulação), hora do dia, tipo de máquina de ressonância magnética (fabricante e força do campo) artefatos de volume e diferentes plataformas de avaliação volumétrica cerebral podem induzir variações que excedem a taxa aceitável de perda anual fisiológica do volume cerebral. Conclusão: Embora seja potencialmente de grande valor, a medida de volume cerebral ainda deve ser vista com cautela na EM.

Palavras-chave: esclerose múltipla; encéfalo; atrofia; substância cinzenta.

Degenerative diseases of the central nervous system (CNS) are characterized by neuron loss and brain and/or spinal cord atrophy. Neurological disability reflects this tissue loss, which must be avoided by all possible means ${ }^{1}$. Multiple sclerosis (MS) research has focused on neuron loss, and treatment of this disease has aimed at controlling its long-term degenerative consequences. For a while, MS was considered to be mostly an inflammatory disease of the white matter, and clinical trial outcomes were directed towards controlling acute demyelinating relapses. More recently, the outcomes of trials have shifted towards increasing the length of time for which patients remain free from physical disability and cognitive dysfunction, since these are the real goals of successful therapies ${ }^{2}$. As we learn more about the disease and the potential ways in which we can positively modify the quality of life of our patients, our demands increase. We now want to avoid all evidence of disease activity and, therefore, decreasing neurodegeneration is an extremely important goal in disease control. "No evidence of disease activity" (NEDA) has become part of the neurologist's vocabulary regarding MS treatment ${ }^{1,2}$. One additional criterion for NEDA is deceleration of brain atrophy, the hallmark of neurodegeneration in $\mathrm{MS}^{3}$. Thus, NEDA-4 would comprise complete control over relapses, disability progression and lesions on magnetic resonance imaging (MRI), together with levels of brain atrophy compatible with those found in the healthy population ${ }^{4}$. Effective treatments for MS can positively interfere with the rate of brain atrophy ${ }^{5}$, which is consistent with our overall aim of the best possible disease control for our patients with MS.

\footnotetext{
'Universidade Metropolitana de Santos, Centro de Referência de Esclerose Múltipla, Departamento de Neurologia, Santos SP, Brasil;

${ }^{2}$ Universidade da Região de Joinville, Departamento de Neuroradiologia, Joinville SC, Brasil;

${ }^{3}$ Universidade da Região de Joinville, Departamento de Neurologia, Joinville SC, Brasil.

Correspondence: Yara Dadalti Fragoso; UNIMES, Departamento de Neurologia da Faculdade de Medicina; Rua da Constituição, 374 ; $11015-470$ Santos SP, Brasil; E-mail:yara@bsnet.com.br

Conflict of interest: There is no conflict of interest to declare.
}

Received 24 November 2016; Received in final form 08 February 2017; Accepted 30 March 2017. 
Although we all want to achieve the same goals, the ways of measuring them are far from resolved. Is a mild, non-incapacitating, short-lasting relapse acceptable in NEDA? Is delayed gadolinium-enhancing assessment required as a measurement to confirm that there is no activity on MRI? Should disability assessment include measurements other than the Expanded Disability Status Scale ${ }^{6}$ ? Does one need to have a specific qualification to assess the Expanded Disability Status Scale, in order to be sure that the patient has reached NEDA? All of these questions are relevant when discussing NEDA. However, with the increased need to control degeneration of the CNS, perhaps the most important question now is "How can we measure brain atrophy in order to assess NEDA-4?" Hundreds of papers, websites and talks discuss the tools for measuring brain atrophy and the importance of integrating this parameter into our daily practice. Are we ready to switch treatments because a patient with MS has not reached NEDA-4? Should we wait and perhaps face patient disabilities because we missed the best moment for drug escalation?

The present paper critically reviews some aspects of volumetric assessment of the brain, of which neurologists need to be aware. All authors individually and comprehensively reviewed each of the aspects listed below in PubMed, Medline, LILACS, SciELO and Google Scholar. The final text was created with full agreement of all authors.

\section{EQUIPMENT}

The MRI equipment used for the patient's assessment may influence the results of brain atrophy measurements? At present, there are dozens of manufacturers producing and commercializing MRI machines (Philips, Siemens, General Electric Healthcare, Fonar, Bruker Biospin, Hitachi Medical Systems of America, Inc., Varian and Toshiba Medical Systems are some of them). Inter-scanner variability should always be taken into consideration when longitudinal examinations are carried out on patients with MS. In fact, two machines of exactly the same model and field strength can also provide results that are significantly different regarding total and regional brain volumes ${ }^{8}$. The morphometric aspects of CNS tissue may be influenced by several instrument-related factors other than scanner manufacturer, such as field strength, imaging magnetic gradients, pulse sequence, coil, number of acquisitions and data processing,9,10,11,12. Intra- and inter-scanner variability may be remarkable: for the same subject, the variability of total brain volume can be $1.4 \%$ in the same scanner and $10.5 \%$ in different scanners ${ }^{13}$. Even upgrading an MRI machine can lead to significantly different assessments of regional grey matter volume ${ }^{14}$.

\section{Artifacts}

It is of essence to establish very clear protocols for MRI scanning of the patient. Artifacts caused by small changes in head or body position may lead to magnified changes in brain volume measurements. Thickness of grey matter, for example, can be greatly affected by head motion ${ }^{15}$. Inconsistent MRI positioning of subjects is common in clinical trials and in daily practice, particularly along the magnet's long Z-axis ${ }^{16}$. The lack of very clear protocols and normative ranges in MRI clinics may influence the results from patients with MS that we use for our assessments ${ }^{17}$. Even small differences in positioning the patient along the magnetic isocenter can significantly decrease the accuracy of morphometric assessments of brain volume ${ }^{16}$.

\section{Pseudo-atrophy and inflammation}

Pseudo-atrophy is another important point for discussion. For example, patients starting treatment for MS may have inflammatory activity associated with edema of the white matter, and subsequent MRI scanning may suggest that atrophy has occurred when this inflammation subsides $^{18}$. The increase in Virchow-Robin spaces, identifiable on MRI among patients with MS in less active phases of the disease, may be a confounder for those who are not aware of this fact ${ }^{19}$. Furthermore, if the protocol for brain volume analyses does not exclude patients who have recently had a relapse (and might even have been treated with corticosteroids), it will be difficult to analyze the effect of edema or water retention in the brain. Patients may have active subclinical inflammation without clinical relapses: could this aggressive pattern of lesions interfere with the volume $e^{20,21}$ ? The definitions and the limits of "recent relapse" and "subclinical aggressive disease" are not at all clear at present as guides for the correct time at which to use volumetric MRI.

\section{Drugs and concomitant diseases}

If the patient takes antipsychotic drugs, the brain volume may decrease faster ${ }^{22}$, while those taking paroxetine ${ }^{23}$ or lithium ${ }^{24}$ may have enlargement of deep grey matter structures. Obstructive sleep apnea may be correlated with severe loss of brain tissue that can be reversed through treatment ${ }^{25}$. In fact, many of the conditions that might affect brain volume are still being identified.

\section{Neuron loss and grey matter thinning}

It is always important to keep in mind that not all measured brain volume loss consists of neuron loss, and not all areas depleted of neuron cells are necessarily shrunk. In fact, neurons account for only $10 \%$ to $20 \%$ of all cells in the cortical grey matter of the brain, which is mainly populated by glia ${ }^{26}$. Even the most precise means of measuring grey matter volume would be assessing at least $80 \%$ glia, rather than neurons.

\section{Hydration}

The level of hydration influences brain volume and function $^{27}$. A session of physical activity without drinking water can cause significant changes in brain morphometry in 
healthy subjects ${ }^{28}$. Automated longitudinal voxelwise analysis methods such as SIENA are sensitive to expansion of ventricles, depending on liquid distribution in the $\mathrm{CNS}^{28}$. In fact, excessive drinking of water or thirsting for a few hours can affect the brain volume to levels that exceed the expected normal aging rate of atrophy ${ }^{29}$. The state of hydration can affect measurements of grey matter, white matter and ventricle volume, to levels that are comparable to those reported in the initial stages of Alzheimer's disease ${ }^{30}$. The changes in brain volume between states of dehydration (overnight without drinking water) and hyper-hydration (drinking 1.5 liters of water) were, on average, $0.36 \%$ in a recent study ${ }^{31}$.

\section{Time of the day}

Diurnal fluctuations in brain morphometry also need to be taken into consideration. Brain volume is greater in the morning and the brain parenchymal fraction was found to change significantly in patients with MS, depending on the time of day that the MRI was performed ${ }^{32}$.

Not only is the time of the day relevant, but also the period of the menstrual cycle may be of importance. Women present with a significant grey matter volume peak and cerebrospinal fluid loss at the time of ovulation ${ }^{33}$. Considering that MS is a typical disease in females of fertile age, this observation may be of importance in assessing brain atrophy in patients with MS.

\section{Platform and tools}

The current measurement of brain volume is the core question in brain atrophy. Even if an examination is totally corrected for a specific type of MRI machine; even if the position of the patient is perfect; and even if the time of day, time of the month and hydration are adjusted using a perfect MRI protocol, the questions regarding the best manner of assessing brain volume on the scanned image would remain.

Many platforms and tools are now available for assessing brain volume, and many more will be developed in the near future. Some are manual, others are automated, and yet others, semi-automated. Some can analyze individual scans, while others require longitudinal follow up of MRI examinations before volumetric data are available. Among the platforms and tools most used for assessing brain volume are the brain parenchymal fraction, Freesurfer, NeuroQuant, Structural Image Evaluation using Normalization of Atrophy (SIENA) and MSMetrix. Variations of up to $3.8 \%$ in volume measurement of grey matter were observed among six different tools due to their specific protocols regarding segmentation ${ }^{34}$. Segmentation can be totally or partially automated and this affects results ${ }^{35}$. Manual editing of data showed significantly better correlation between grey matter thickness in MRI and postmortem samples than did fully automated techniques ${ }^{36}$.

A short discussion on the evidence that these tools provide for assessing the brains of patients with MS follows below, considering each tool individually.
Brain Parenchymal Fraction: This is defined as the ratio of brain parenchymal volume to the total volume within the brain surface contour. The brain parenchymal fraction uses automatic segmentation algorithms that are checked by experienced radiologists. It is time-consuming and the ratios relating to grey matter, white matter and cerebrospinal fluid volumes are calculated individually. The software has been in use since the 1990s. There are few papers reporting on the brain parenchymal fraction for patients with MS, and they typically discuss data on small numbers of cases ${ }^{37}$. Fully automated software tools like SyMap with principles similar to those of the brain parenchymal fraction are now being studied in relation to $\mathrm{MS}^{38}$.

Freesurfer: This is a freely available tool that can be used to assess brain volume in cross-sectional or longitudinal studies. The method has been used in some clinical trials and ad-hoc publications ${ }^{39}$, and the data on MS included many patients. However, the tool is complex to learn and to use in daily practice, and uploading data on the platform is excessively timeconsuming ${ }^{40}$. Freesurfer is mostly used only in research.

NeuroQuant: This has been used in many studies on cognitive disorders and dementia, but few data on MS have been published using this tool ${ }^{41}$.

Structural Image Evaluation using Normalization of Atrophy (SIENA): This is the software that has been most used for assessing brain volume in MS, and it has been used in clinical trials and in research centers of excellence ${ }^{4}$. The SIENA estimates the percentage brain volume change between two input images of the same subject, produced at different points in time, while the SIENAX version can assess cross-sectional data ${ }^{42}$.

MSMetrics: This is a newer program, described as a reliable automated method for lesion segmentation, independent of the use of an MRI scanner or acquisition protocol ${ }^{43}$. The MSmetrix does not require manual interface and/or training and seems to be more accurate than SIENA when different field strengths are used ${ }^{44}$. When MSMetrics, SIENA and NeuroQuant are compared, the level of discrepancy among them varies from $1 \%$ to $5.5 \%^{41}$. There are very few studies on brain volume in MS using this tool, which requires a private license for use.

\section{DISCUSSION}

It is common knowledge that neurons should be spared at all costs. Any disease that leads to neuron death may render the patient subject to severe and permanent disabilities. In MS, treatments that control acute relapses improve the long-term prognosis of the disease ${ }^{45}$, and treatments that decrease the brain atrophy rate may also be important for the prognosis of $\mathrm{MS}^{46}$. Longitudinal assessments on patients with MS are important for identifying subclinical disease activity. Irrespective of the signs and symptoms of acute demyelination, an increased lesion load observed on MRI suggests that the disease is not under control. In the 
presence of new lesions in T2, and particularly in the presence of gadolinium-enhanced lesions in $\mathrm{T} 1$, it is common knowledge that MS is active at a subclinical level. Therefore, with the present knowledge, all neurologists aim to achieve the best possible control over relapses, disability progression and lesions on MRI. This triad is known as "no evidence of disease activity", or NEDA, for short. Despite criticism of the choice of wording ${ }^{47,48,49}$, all neurologists and patients aim to reach NEDA in MS. More recently, addition of a fourth criterion within NEDA has brought about discussion of NEDA-4, i.e. NEDA plus decreased rates of brain atrophy.

While the principle of NEDA-4 is honorable, it is worrying to observe that patients are having their medications switched because they have not achieved NEDA-4, or are being reassured that their disease is under complete control. How sure are we of brain atrophy measurements? With so many parameters that must be controlled in order to make morphometric assessments of the brain, can we accept NEDA-4 as the ultimate aim in MS therapy? Recent and methodologically sound data suggest that estimation of brain atrophy in patients with MS is only possible after several years of longitudinal observation ${ }^{50}$. In real-life medical practice, the methodological and technical confounders make it difficult to use brain atrophy measurements in their present form, for guiding therapeutic decisions ${ }^{51,52,53}$. Data from patients enrolled in clinical trials come from very rigorous protocols: the equipment, the researchers, the assessments, and the whole protocol for data acquisition and interpretation are strict. The same cannot be said for daily medical practice, where patients do not necessarily go to the same image clinic or are not seen by the same doctor year after year. Can we really talk about NEDA-4 as the ideal outcome for MS treatment in the real world?

An acceptable rate of brain volume loss for an aging healthy adult is of the order of $0.4 \%$ per year, and values higher than this are now considered to be red flags for the therapeutic success of a treatment for $\mathrm{MS}^{4}$. Recent papers have suggested that therapeutic decisions to implement drug switching may be made if the rate of brain atrophy is high in $\mathrm{MS}^{54}$. We, the authors of the present paper, do not agree with this. At present, the variations among protocols used for measuring brain volume go from $0.3 \%$ to $5.5 \%$. A study on teriflunomide that showed that this drug had no effect on brain atrophy, showed reduced rates of brain atrophy when another platform was used for brain morphometry ${ }^{55,56}$. The same two platforms that gave these different results for teriflunomide (brain parenchymal fraction and SIENA) were considered to be the only reliable tools for assessing brain volume in a recent meta-analysis in which all the results from both of them were pooled ${ }^{57}$. If grey matter is the subject of investigation, variations are wide among methods used for analyses ${ }^{35,36,37}$, and several years of follow up may be necessary for conclusions ${ }^{50}$. On the other hand, cortical atrophy in MS occurs largely in a non-random manner and seems to affect distinct anatomical areas ${ }^{58,59}$. It is essential to continue to study and to improve our understanding.

In conclusion, it is of paramount importance to discuss and to understand the advantages and limitations of brain volumetric studies in MS. In the future, volumetric studies in the CNS of patients with MS may help guide treatment. However, at least for the time being, therapeutic decisions based upon brain atrophy should be taken with a pinch of salt.

References

1. Havrdova E, Galetta S, Stefoski D, Comi G. Freedom from disease activity in multiple sclerosis. Neurology. 2010;74(17 Suppl 3):S3-7. https://doi.org/10.1212/WNL.0b013e3181dbb51c

2. Gold R, Hartung HP, Stangel M, Wiendl H, Zipp F. Therapeutic goals of baseline and escalation therapy for relapsing-remitting multiple sclerosis. Aktuelle Neurol. 2012;39(7):342-50. https://doi.org/10.1055/s-0032-1305248

3. Kappos L, De Stefano N, Freedman MS, Cree BA, Radue EW, Sprenger T et al. Inclusion of brain volume loss in a revised measure of 'no evidence of disease activity' (NEDA-4) in relapsing-remitting multiple sclerosis. Mult Scler. 2016;22(10):1297-305. https://doi.org/10.1177/1352458515616701

4. De Stefano N, Stromillo ML, Giorgio A, Bartolozzi ML, Battaglini M, Baldini M et al. Establishing pathological cut-offs of brain atrophy rates in multiple sclerosis. J Neurol Neurosurg Psychiatry. 2016;87(1):93-9. https://doi.org/10.1136/jnnp-2014-309903

5. Sormani MP, Arnold DL, De Stefano N. Treatment effect on brain atrophy correlates with treatment effect on disability in multiple sclerosis. Ann Neurol. 2014;75(1):43-9. https://doi.org/10.1002/ana.24018

6. Kurtzke JF. Rating neurologic impairment in multiple sclerosis: an expanded disability status scale (EDSS). Neurology. 1983;33(11):1444-52. https://doi.org/10.1212/WNL.33.11.1444
7. Jovicich J, Czanner S, Han X, Salat D, Kouwe A, Quinn B et al. MRI-derived measurements of human subcortical, ventricular and intracranial brain volumes: reliability effects of scan sessions, acquisition sequences, data analyses, scanner upgrade, scanner vendors and field strengths. Neuroimage. 2009;46(1):177-92. https://doi.org/10.1016/j.neuroimage.2009.02.010

8. Takao H, Hayashi N, Ohtomo K. Effect of scanner in longitudinal studies of brain volume changes. J Magn Reson Imaging. 2011;34(2):438-44. https://doi.org/10.1002/jmri.22636

9. Jovicich J, Czanner S, Greve D, Haley E, Kouwe A, Gollub R et al. Reliability in multi-site structural MRI studies: effects of gradient non-linearity correction on phantom and human data. Neuroimage. 2006;30(2):436-43. https://doi.org/10.1016/j.neuroimage.2005.09.046

10. Han X, Jovicich J, Salat D, Kouwe A, Quinn B, Czanner S et al. Reliability of MRI-derived measurements of human cerebral cortical thickness: the effects of field strength, scanner upgrade and manufacturer. Neuroimage. 2006;32(1):180-94. https://doi.org/10.1016/j.neuroimage.2006.02.051

11. Streitbürger DP, Pampel A, Krueger G, Lepsien J, Schroeter ML, Mueller Ket al. Impact of image acquisition on voxel-based-morphometry investigations of age-related structural brain changes. Neuroimage. 2014;87:170-82. https://doi.org/10.1016/j.neuroimage.2013.10.051 
12. Chu R, Tauhid S, Glanz BI, Healy BC, Kim G, Oommen VV et al. Whole Brain Volume Measured from 1.5T versus 3T MRI in healthy subjects and patients with multiple sclerosis. J Neuroimaging. 2016;26(1):62-7. https://doi.org/10.1111/jon.12271

13. Huppertz HJ, Kröll-Seger J, Klöppel S, Ganz RE, Kassubek J. Intra- and interscanner variability of automated voxel-based volumetry based on a 3D probabilistic atlas of human cerebral structures. Neuroimage. 2010;49(3):2216-24. https://doi.org/10.1016/j.neuroimage.2009.10.066

14. Takao H, Hayashi N, Ohtomo K. Effects of the use of multiple scanners and of scanner upgrade in longitudinal voxel-based morphometry studies. J Magn Reson Imaging. 2013;38(5):1283-91. https://doi.org/10.1002/jmri.24038

15. Reuter M, Tisdall MD, Qureshi A, Buckner RL, van der Kouwe AJ, Fischl B. Head motion during MRI acquisition reduces gray matter volume and thickness estimates. Neuroimage. 2015;107:107-15. https://doi.org/10.1016/j.neuroimage.2014.12.006

16. Caramanos Z, Fonov VS, Francis SJ, Narayanan S, Pike GB, Collins DL et al. Gradient distortions in MRI: characterizing and correcting for their effects on SIENA-generated measures of brain volume change. Neuroimage. 2010;49(2):1601-11. https://doi.org/10.1016/j.neuroimage.2009.08.008

17. Brewer JB. Fully-automated volumetric MRI with normative ranges: translation to clinical practice. Behav Neurol. 2009;21(1):21-8. https://doi.org/10.1155/2009/616581

18. Vidal-Jordana A, Sastre-Garriga J, Pérez-Miralles F, Tur C, Tintoré M, Horga A et al. Early brain pseudoatrophy while on natalizumab therapy is due to white matter volume changes. Mult Scler. 2013;19(9):1175-81. https://doi.org/10.1177/1352458512473190

19. Conforti R, Cirillo M, Saturnino PP, Gallo A, Sacco R, Negro A et al. Dilated Virchow-Robin spaces and multiple sclerosis: 3 T magnetic resonance study. Radiol Med (Torino). 2014;119(6):408-14. https://doi.org/10.1007/s11547-013-0357-9

20. Battaglini M, Jenkinson M, De Stefano N. Evaluating and reducing the impact of white matter lesions on brain volume measurements. Hum Brain Mapp. 2012;33(9):2062-71. https://doi.org/10.1002/hbm.21344

21. Koudriavtseva T, Mainero C. Brain atrophy as a measure of neuroprotective drug effects in multiple sclerosis: influence of inflammation. Front Hum Neurosci. 2016;10:226. https://doi.org/10.3389/fnhum.2016.00226

22. Ho BC, Andreasen NC, Ziebell S, Pierson R, Magnotta V. Long-term antipsychotic treatment and brain volumes: a longitudinal study of first-episode schizophrenia. Arch Gen Psychiatry. 2011;68(2):128-37. https://doi.org/10.1001/archgenpsychiatry.2010.199

23. Talati A, Pantazatos SP, Hirsch J, Schneier F. A pilot study of gray matter volume changes associated with paroxetine treatment and response in social anxiety disorder. Psychiatry Res. 2015;231(3):279-85. https://doi.org/10.1016/j.pscychresns.2015.01.008

24. Hajek T, Weiner MW. Neuroprotective Effects of Lithium in Human Brain? Food for Thought. Curr Alzheimer Res. 2016;13(8):862-72. https://doi.org/10.2174/1567205013666160219112712

25. Kim H, Joo E, Suh S, Kim JH, Kim ST, Hong SB. Effects of long-term treatment on brain volume in patients with obstructive sleep apnea syndrome. Hum Brain Mapp. 2016;37(1):395-409. https://doi.org/10.1002/hbm.23038

26. Herculano-Houzel S. The human brain in numbers: a linearly scaled-up primate brain. Front Hum Neurosci. 2009;3:31. https://doi.org/10.3389/neuro.09.031.2009

27. Kempton MJ, Ettinger U, Foster R, Williams SC, Calvert GA, Hampshire A et al. Dehydration affects brain structure and function in healthy adolescents. Hum Brain Mapp. 2011;32(1):71-9. https://doi.org/10.1002/hbm.20999

28. Kempton MJ, Ettinger U, Schmechtig A, Winter EM, Smith L, McMorris T et al. Effects of acute dehydration on brain morphology in healthy humans. Hum Brain Mapp. 2009;30(1):291-8. https://doi.org/10.1002/hbm.20500

29. Duning T, Kloska S, Steinsträter O, Kugel H, Heindel W, Knecht S. Dehydration confounds the assessment of brain atrophy. Neurology. 2005;64(3):548-50. https://doi.org/10.1212/01.WNL.0000150542.16969.CC
30. Streitbürger DP, Möller HE, Tittgemeyer M, Hund-Georgiadis M, Schroeter ML, Mueller K. Investigating structural brain changes of dehydration using voxel-based morphometry. PLoS One. 2012;7(8):e44195. https://doi.org/10.1371/journal.pone.0044195

31. Nakamura K, Brown RA, Araujo D, Narayanan S, Arnold DL. Correlation between brain volume change and $\mathrm{T} 2$ relaxation time induced by dehydration and rehydration: implications for monitoring atrophy in clinical studies. Neuroimage Clin. 2014;6:166-70. https://doi.org/10.1016/j.nicl.2014.08.014

32. Nakamura K, Brown RA, Narayanan S, Collins DL, Arnold DL. Diurnal fluctuations in brain volume: statistical analyses of MRI from large populations. Neuroimage. 2015;118:126-32. https://doi.org/10.1016/j.neuroimage.2015.05.077

33. Hagemann G, Ugur T, Schleussner E, Mentzel HJ, Fitzek C, Witte OW et al. Changes in brain size during the menstrual cycle. PLoS One. 2011;6(2):e14655. https://doi.org/10.1371/journal.pone.0014655

34. Derakhshan M, Caramanos Z, Giacomini PS, Narayanan S, Maranzano J, Francis SJ et al. Evaluation of automated techniques for the quantification of grey matter atrophy in patients with multiple sclerosis. Neuroimage. 2010;52(4):1261-7. https://doi.org/10.1016/j.neuroimage.2010.05.029

35. Popescu V, Schoonheim MM, Versteeg A, Chaturvedi N, Jonker M, Menezes RX et al. Grey matter atrophy in multiple sclerosis: clinical interpretation depends on choice of analysis method. PLoS One. 2016;11(1):e0143942. https://doi.org/10.1371/journal.pone.0143942

36. Popescu V, Klaver R, Versteeg A, Voorn P, Twisk JW, Barkhof $F$ et al. Postmortem validation of MRI cortical volume measurements in MS. Hum Brain Mapp. 2016;37(6):2223-33. https://doi.org/10.1002/hbm.23168

37. Rudick RA, Fisher E, Lee JC, Simon J, Jacobs L. Use of the brain parenchymal fraction to measure whole brain atrophy in relapsing-remitting MS. Neurology. 1999;53(8):1698-704. https://doi.org/10.1212/WNL.53.8.1698

38. Vågberg M, Lindqvist T, Ambarki K, Warntjes JB, Sundström P, Birgander R et al. Automated determination of brain parenchymal fraction in multiple sclerosis. AJNR Am J Neuroradiol. 2013;34(3):498-504. https://doi.org/10.3174/ajnr.A3262

39. Narayana PA, Govindarajan KA, Goel P, Datta S, Lincoln JA, Cofield SS et al. Regional cortical thickness in relapsing remitting multiple sclerosis: A multi-center study. Neuroimage Clin. 2012;2:120-31. https://doi.org/10.1016/j.nicl.2012.11.009

40. Govindarajan KA, Datta S, Hasan KM, Choi S, Rahbar MH, Cofield SS et al. Effect of in-painting on cortical thickness measurements in multiple sclerosis: A large cohort study. Hum Brain Mapp. 2015;36(10):3749-60. https://doi.org/10.1002/hbm.22875

41. Wang C, Beadnall HN, Hatton SN, Bader G, Tomic D, Silva DG et al. Automated brain volumetrics in multiple sclerosis: a step closer to clinical application. J Neurol Neurosurg Psychiatry. 2016;87(7):754-7. https://doi.org/10.1136/jnnp-2015-312304

42. Smith SM, Zhang Y, Jenkinson M, Chen J, Matthews PM, Federico A et al. Accurate, robust, and automated longitudinal and cross-sectional brain change analysis. Neuroimage. 2002;17(1):479-89. https://doi.org/10.1006/nimg.2002.1040

43. Jain S, Sima DM, Ribbens A, Cambron M, Maertens A, Van Hecke W et al. Automatic segmentation and volumetry of multiple sclerosis brain lesions from MR images. Neuroimage Clin. 2015;8:367-75. https://doi.org/10.1016/j.nicl.2015.05.003

44. Lysandropoulos AP, Absil J, Metens T, Mavroudakis N, Guisset F, Van Vlierberghe E et al. Quantifying brain volumes for Multiple Sclerosis patients follow-up in clinical practice - comparison of 1.5 and 3 Tesla magnetic resonance imaging. Brain Behav. 2016;6(2):e00422. https://doi.org/10.1002/brb3.422

45. Goodin DS, Reder AT, Bermel RA, Cutter GR, Fox RJ, Lublin FD et al. Relapses in multiple sclerosis: Relationship to disability. Mult Scler Relat Disord. 2016;6:10-20. https://doi.org/10.1016/j.msard.2015.09.002 
46. Ziemssen T, Derfuss T, Stefano N, Giovannoni G, Palavra F, Tomic D et al. Optimizing treatment success in multiple sclerosis.J Neurol. 2016;263(6):1053-65. https://doi.org/10.1007/s00415-015-7986-y

47. Fragoso YD. Why some of us do not like the expression "no evidence of disease activity" (NEDA) in multiple sclerosis. Mult Scler Relat Disord. 2015;4(4):383-4. https://doi.org/10.1016/j.msard.2015.06.009

48. Freedman MS. Are we in need of NEDA? Mult Scler. 2016;22(1):5-6. https://doi.org/10.1177/1352458515617249

49. Damasceno A, Damasceno BP, Cendes F. No evidence of disease activity in multiple sclerosis: implications on cognition and brain atrophy. Mult Scler. 2016;22(1):64-72. https://doi.org/10.1177/1352458515604383

50. Biberacher V, Schmidt P, Keshavan A, Boucard CC, Righart R, Sämann $P$ et al. Intra- and interscanner variability of magnetic resonance imaging based volumetry in multiple sclerosis. Neuroimage. 2016;142:188-97. https://doi.org/10.1016/j.neuroimage.2016.07.035

51. Barkhof F. Brain atrophy measurements should be used to guide therapy monitoring in MS - NO. Mult Scler. 2016;22(12):1524-6. https://doi.org/10.1177/1352458516649452

52. Azevedo CJ, Pelletier D. Whole-brain atrophy: ready for implementation into clinical decision-making in multiple sclerosis? Curr Opin Neurol. 2016;29(3):237-42. https://doi.org/10.1097/WC0.0000000000000322

53. Smith TB, Nayak KS. MRI Artifacts and correction strategies. Imaging Med. 2010;2(4):445-57. https://doi.org/10.2217/iim.10.33
54. Zivadinov R, Dwyer MG, Bergsland N. Brain atrophy measurements should be used to guide therapy monitoring in MS - YES. Mult Scler. 2016;22(12):1522-4. https://doi.org/10.1177/1352458516649253

55. Miller AE. Teriflunomide: a once-daily oral medication for the treatment of relapsing forms of multiple sclerosis. Clin Ther. 2015;37(10):2366-80. https://doi.org/10.1016/j.clinthera.2015.08.003

56. Radue EW, Sprenger T, Gaetano L, Mueller-Lenke N, Wuerfel J, Thangavelu K et al. Teriflunomide slows brain volume loss in relapsing MS: a SIENA analysis of the TEMSO MRI dataset. Neurology. 2016;86(16 Suppl).

57. Valverde S, Oliver A, Roura E, Pareto D, Vilanova JC, Ramió-Torrentà $L$ et al. Quantifying brain tissue volume in multiple sclerosis with automated lesion segmentation and filling. Neuroimage Clin. 2015;9:640-7. https://doi.org/10.1016/j.nicl.2015.10.012

58. Steenwijk MD, Geurts JJ, Daams M, Tijms BM, Wink AM, Balk LJ et al. Cortical atrophy patterns in multiple sclerosis are non-random and clinically relevant. Brain. 2016;139(1):115-26. https://doi.org/10.1093/brain/awv337

59. De Stefano N, Airas L, Grigoriadis N, Mattle HP, O'Riordan J, Oreja-Guevara $\mathrm{C}$ et al. Clinical relevance of brain volume measures in multiple sclerosis. CNS Drugs. 2014;28(2):147-56. https://doi.org/10.1007/s40263-014-0140-z 